\title{
PENGARUH MOTIVASI BELAJAR DAN ADVERSITY QUOTIENT TERHADAP HASIL BELAJAR MATEMATIKA SISWA KELAS VII SMP NEGERI 10 SAMARINDA TAHUN AJARAN 2019/2020
}

\author{
Haeruddin $^{1)}$ \\ Hadijah \\ ${ }^{1)}$ Dosen Pendidikan Matematika FKIP Universitas Mulawarman \\ Email: ${ }^{1)}$ haeruddin22@gmail.com
}

\begin{abstract}
ABSTRAK
Jenis penelitian ini adalah penelitian ex post facto dengan tujuan untuk mengetahui pengaruh motivasi belajar $\left(X_{1}\right)$ dan adversity quotient $\left(X_{2}\right)$ terhadap hasil belajar matematika $(Y)$ siswa kelas VII SMP Negeri 10 Samarinda tahun ajaran 2019/2020. Populasi dalam penelitian ini adalah seluruh siswa kelas VII SMP Negeri 10 Samarinda, yang terdiri dari 11 kelas dengan jumlah siswa sebanyak 325 siswa. Teknik pengambilan sampel dalam penelitian ini adalah teknik cluster sampling, sehingga sampel terdiri dari 6 kelas. Instrumen penelitian berupa angket dan tes. Sedangkan teknik analisis data yang digunakan adalah statistik deskriptif dan inferensial dengan taraf signifikan $(\alpha)$ sebesar 5\%. Berdasarkan hasil analisis deskriptif diperoleh nilai rata-rata dari data motivasi belajar sebesar 75,83 tergolong kategori sedang, nilai rata-rata data adversity quotient sebesar 53,36\% tergolong kategori sedang, dan nilai rata-rata dari hasil belajar matematika siswa adalah 59,33 yang dikategorikan kurang. Dari hasil analisis menggunakan analisis jalur diperoleh sub-struktur 1 signifikan sehingga terdapat pengaruh motivasi belajar terhadap adversity quotient dengan besar kontribusi $29,7 \%$. Sub-struktur 2 signifikan sehingga terdapat pengaruh motivasi belajar terdapat hasil belajar matematika dengan besar kontribusi 2,2\% dan terdapat pengaruh adversity quotient terdapat hasil belajar matematika dengan besar kontribusi 33,9\%. Berdasarkan analisis inferensial, maka disimpulkan bahwa motivasi belajar dan adversity quotient berpengaruh terhadap hasil belajar matematika siswa kelas VII SMP Negeri 10 Samarinda tahun ajaran 2019/2020. Motivasi belajar dapat menaikkan adversity quotient dan meningkatkan hasil belajar matematika sedangkan adversity quotient dapat meningkatkan hasil belajar matematika siswa.
\end{abstract}

Kata kunci: Motivasi Belajar, Adversity Quotient, Hasil Belajar Matematika

\begin{abstract}
This type of research is ex post facto research, which aims to determine the effect of study motivation $\left(\mathrm{X}_{1}\right)$, adversity quotient $\left(\mathrm{X}_{2}\right)$ on the mathematics learning outcomes $(\mathrm{Y})$ of VII grade of SMP Negeri 10 Samarinda. The population in this study were all VII grade students of SMP Negeri 10 Samarinda in the 2019/2020 school year, consisting of 11 classes which numbered 325 students. The sampling technique in this study was the cluster sampling technique, so the sample consists of 6 classes. The instruments in this study were questionnaires and tests. Questionnaire techniques are used to obtaining data on study motivation and adversity quotient, while tests are used to obtaining data on learning
\end{abstract}


outcomes in mathematics. The data analysis technique used in this study was descriptive statistics and inferential statistics with a significant level $(\alpha)$ of $5 \%$. Based on the result of the descriptive analysis the following results were obtained, the average value of the study motivation research data was 75.83 calssified as the moderate category and the average value of the research results of the adversity quotient was 53.36 classified as the moderate category. The average value of student mathematics learning outcomes is 59.33. Which means that the learning outcomes of students in grade VII in SMP Negeri 10 Samarinda are in the less category. From the results of the analysis using path analysis, obtained substructure 1 is showed significant so there is an influence of study motivation on adversity quotient with the percentage of contribution was 29,7\%. Sub-structure 2 is showed significant so there is an influence of study motivation on the mathematics learning outcomes with the percentage of contribution is $2,2 \%$ and also there is an influence of adversity quotient on the mathematics learning outcomes with the percentage of contribution is $33,9 \%$. Based on inferential analysis, it can be concluded the there are influences of study motivation and adversity quotient on the learning outcomes of the VII grade of SMP Negeri 10 Samarinda academic year 2019/2020.

Keywords: Study Motivation, Adversity Quotient, Mathematics Learning

\section{PENDAHULUAN}

Pendidikan memiliki peran yang sangat penting dalam meningkatkan kemajuan bangsa untuk mewujudkan citacita bangsa Indonesia yang tercantum dalam pembukaan UUD 1945 alinea ke-4. Pendidikan menjadi salah satu tumpuan agar menghasilkan manusia yang dapat bertahan dalam perubahan zaman yang semakin kompleks.

Peserta didik yang terdaftar di sekolah tidak hanya sekedar status melainkan harus memiliki rasa tanggungjawab yang besar, karena bangsa menggantungkan harapan besar kepada mereka. Peserta didik di masa yang akan datang diharapkan mampu menjadi seseorang yang dapat memberikan solusi untuk setiap permasalahan yang dihadapi masyarakat. Peserta didik yang diharapkan oleh masyarakat adalah peserta didik yang tidak mudah goyah, tidak mudah menyerah seiring dengan kesulitan dan hambatan yang semakin besar.

Berdasarkan hasil observasi yang dilakukan, hasil belajar matematika siswa masih tergolong rendah hal ini diungkapkan oleh Guru kelas VII SMP Negeri 10 Samarinda. Beliau mengatakan nilai ratarata siswa masih belum memenuhi Kriteria Ketuntasan Minimum (KKM). Berdasarkan hasil observasi yang dilakukan di SMP Negeri 10 Samarinda, saat guru mengajar ada siswa yang tidak memperhatikan, siswa lebih memilih bercerita, bermain dengan teman sebangkunya atau hanya diam melamun. Ada juga siswa yang menganggu temannya padahal temannya sedang memperhatikan guru.

Motivasi merupakan faktor penting yang dibutuhkan oleh setiap individu untuk mencapai tujuan yang telah ditetapkan. Begitu pula bagi seorang siswa, motivasi merupakan hal yang mendasar dari sebuah keterampilan mental yang dimiliki setiap 
siswa dalam usaha mencapai tujuan mereka. Keberhasilan yang baik pasti ditunjukkan dengan adanya motivasi yang baik pula sehingga akan memungkinkan seorang siswa meraih tujuannya.

Setiap individu yang memiliki motivasi yang tinggi akan memiliki komitmen yang kuat dalam usahanya menampilkan kemampuannya. Hal ini karena motivasi merupakan tenaga pendorong, atau sumber kekuatan dari suatu perbuatan, perilaku, atau penampilan, Adisasmito (2007:31). Motivasi terjadi apabila seseorang mempunyai keinginan dan kemauan untuk melakukan sesuatu kegiatan atau tindakan dalam rangka mencapai tujuan tertentu, Uno (2013:6). Ada tiga ciri pokok dari motivasi yaitu direction, intensitas, dan persisten dalam berperilaku, Komarudin (2013:24). Direction menunjukkan bentuk aktivitas yang dipilih untuk dilakukan untuk mencapai tujuan, intensitas merujuk pada seberapa besar usaha yang dilakukan untuk setiap aktivitas tersebut, persisten menggambarkan waktu yang digunakan dalam melakukan aktivitas tersebut.

Berdasarkan kajian pendapat para ahli tantang motivasi belajar, aspek-aspek berikut yang akan digunakan untuk membuat inbdikator dalam penelitian ini: (1) adanya hasrat dan keinginan untuk belajar, (2) adanya dorongan dan kebutuhan blajar, (3) adanya semangat dan kebutuhan belajar, (4) adanya penghargaan dalam belajar, dan (5) adanya kegiatan menarik dalam belajar.

Secara sederhana, adversity quotient dapat diartikan sebagai daya juang (Departemen Pendidikan Nasional, 2007) yaitu kemampuan mempertahankan atau mencapai sesuatu yang dilakukan dengan gigih. Adz-Dzakiey (2008:677) menyebutkan dalam bukunya yang berjudul Prophetic Intelligence bahwa adversity quotient merupakan suatu potensi yang mana dengan potensi tersebut seseorang dapat mengubah hambatan uang dihadapinya menjadi peluang.

Stoltz (2004:14) mengungkapkan bahwa intelligent quotient, spiritual quotient dan emotional quotient saja tidak cukup untuk mencapai kesuksesan. Adversity Quotient merupakan kecerdasan menghadap kesulitan atau hambatan dan kemampuan bertahan dalam berbagai kesulitan hidup dan tantangan yang dialami.

Nashori (2007:47) berpendapat bahwa adversity quotient merupakan kemampuan seseorang dalam menggunakan kecerdasannya untuk mengarahkan, mengubah cara berpikir dan tindakannya ketika menghadapi hambatan dan kesulitan yang bisa menyengsarakan dirinya. Stoltz (dalam Amir dan Risnawati, 2016:176) mengungkapkan adversity quotient (daya juang) merupakan faktor yang paling menentukan bagi kesuksesan jasmani maupun rohani, karena pada dasarnya setiap orang memendam hasrat untuk mencapai kesuksesan.

Daya Juang menurut teori Adleri (dalam Amir dan Risnawati, 2016:177) merupakan kompensasi (striving force as compensation) dimana manusia memiliki daya juang sejak lahir. Potensi berjuang manusia untuk mencapai sebuah tujuan tersebut merupakan kompensasi dari rasa inferior (rendah diri), sehingga daya juang harus diasah dan dikembangkan, agar jiwa manusia menjadi sehat dan seimbang. Adler juga mengatakan bahwa manusia dapat 
berjuang untuk kepentingan pribadinya dan lingkungannya.

Dari uraian di atas, dapat disimpulkan indikator daya juang yang akan diukur dalam penelitian ini adalah (1) kendali, daya tahan, (3) jangkauan, (4) asal-usul dan pengakuan.

Hasil belajar matematika adalah perubahan tingkah laku yang dicapai siswa setelah melakukan kegiatan pembelajaran matematika, yang dinyatakan dalam bentuk nilai berdasarkan tes hasil belajar matematika. Perubahan tingkah laku meliputi tiga ranah yaitu ranah kognitif, ranah afektif, dan ranah psikomotorik.

\section{METODE PENELITIAN}

Jenis penelitian yang digunakan adalah penelitian kuantitatif dengan metode ex post facto. Penelitian ini terdiri dua variabel kelas VII SMP Negeri 10 Samarinda yang terdiri dari 11 kelas dengan jumlah 325 siswa. Adapun kelas sampelnya terdiri dari 6 kelas.

Peneliti menggunakan teknik pengumpulan data berupa angket dan tes. Angket digunakan untuk memperoleh data motivasi belajar dan adversity quotient. Tes digunakan untuk memperoleh data hasil belajar matematika siswa. Tes digunakan untuk memperoleh data hasil belajar matematika siswa. Statistik deskriptif digunakan untuk mengungkapkan distribusi skor dari masing-masing variabel. Statistik inferensial menggunakan analisis jalur. Sebelum pengujian hipotesis terlebih dahulu dilakukan uji asumsi yang terdiri dari uji normalitas residual, uji heteroskedastisitas, uji multikolinearitas, dan uji autokorelasi. Setelah pengujian asumsi ter-

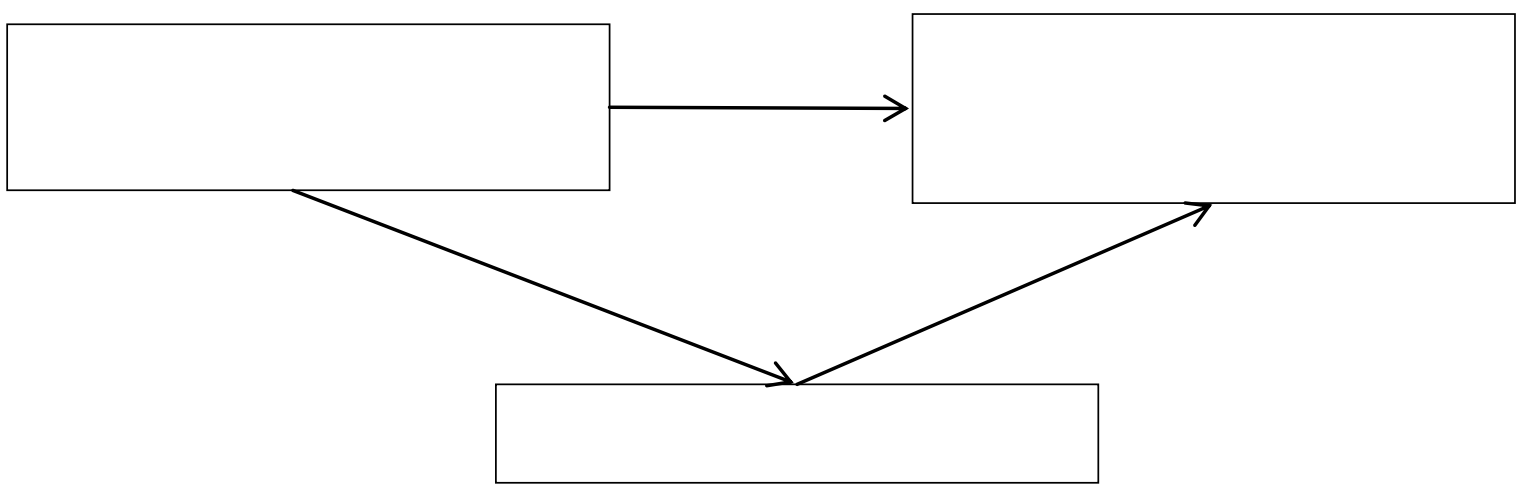

Gambar 1. Rancangan penelitian

bebas yaitu motivasi belajar $\left(X_{1}\right)$ dan adversity quotient $\left(X_{2}\right)$ dan satu variabel terikat yaitu hasil belajar matematika $(Y)$. Model rancangan penelitian ini ditunjukkan pada gambar 1 .

Penelitian ini dilaksanakan pada tahun ajaran 2019/2020 bulan Agustus. Populasi dalam penelitian ini adalah siswa penuhi, kemudian menguji hipotesis penelitian menggunakan analisis jalur dengan taraf signifikan pengujian $5 \%$.

HASIL PENELITIAN DAN PEMBAHASAN

\section{A. Deskripsi Data}


Data motivasi belajar dalam penelitian ini diukur dengan menggunakan angket yang terdiri dari 30 butir pernyataan. Deskripsi data variabel ini dapat dilihat pada tabel 1. Berdasarkan tabel tersebut, diketahui bahwa skor motivasi belajar paling banyak berada pada kategori sedang sehingga dapat dinyatakan bahwa kondisi motivasi belajar siswa kelas VII SMP Negeri 10 Samarinda tergolong sedang.
Data variabel adversity quotient dalam penelitian ini diukur dengan menggunakan angket yang terdiri dari 30 butir pernyataan. Deskripsi data variabel ini dapat dilihat pada tabel 2. Berdasarkan hasil tersebut diketahui bahwa skor adversity quotient berada pada kategori sedang sehingga dapat dinyatakan bahwa kondisi adversity quotient siswa kelas VII SMP Negeri 10 Samarinda tergolong sedang.

Tabel 1. Distribusi data motivasi belajar

\begin{tabular}{|c|c|}
\hline Interval & Kategori \\
\hline$X \leq 56,22$ & Sangat Rendah \\
\hline $56,22<X \leq 69,29$ & Rendah \\
\hline $69,29<X \leq 82,37$ & Sedang \\
\hline $82,37<X \leq 95,44$ & Tinggi \\
\hline $95,44<X$ & Sangat Tinggi \\
\hline
\end{tabular}

Tabel 2. Distribusi data adversity quotient

\begin{tabular}{|c|c|}
\hline Interval & Kategori \\
\hline$X \leq 31,73$ & Sangat Rendah \\
\hline $31,73<X \leq 46,15$ & Rendah \\
\hline $46,15<X \leq 60,57$ & Sedang \\
\hline $60,57<X \leq 74,99$ & Tinggi \\
\hline $74,99<X$ & Sangat Tinggi \\
\hline
\end{tabular}

Tabel 3. Distribusi data hasil belajar

\begin{tabular}{|c|c|c|c|}
\hline \multicolumn{2}{|c|}{ Skor Hasil Belajar } & \multirow{2}{*}{ Frekuensi } & Persentase(\%) \\
\hline Interval & Katerogi & & $1,7 \%$ \\
\hline $90<X \leq 100$ & Sangat Baik & 3 & $7,2 \%$ \\
\hline $82<X \leq 90$ & Baik & 13 & $9,4 \%$ \\
\hline $75 \leq X \leq 82$ & Cukup & 17 & $81,7 \%$ \\
\hline$X<75$ & Kurang & 147 & $100 \%$ \\
\hline \multicolumn{2}{|c|}{ Jumlah } & 180 & 96,00 \\
\hline \multicolumn{2}{|c|}{ Skor Maksimum } & \multicolumn{2}{c|}{19,00} \\
\hline \multicolumn{2}{|c|}{ Skor Minimum } & \multicolumn{2}{c|}{17,06} \\
\hline \multicolumn{2}{|c|}{ Rata-rata } & \multicolumn{2}{c}{} \\
\hline \multicolumn{2}{|c|}{ Standar Deviasi }
\end{tabular}


Data hasil belajar matematika dalam penelitian ini diukur dengan menggunakan 5 soal uraian. Deskripsi data variabel ini dapat dilihat pada tabel 3. Berdasarkan hasil tersebut diketahui bahwa skor hasil belajar matematika paling banyak berada pada kategori kurang sehingga dapat dinyatakan bahwa kondisi hasil belajar matematika siswa kelas VII SMP Negeri 10 samarinda tergolong sedang.

\section{B. Statistik Inferensial}

1. Uji normalitas

Berdasarkan hasil analisis dengan menggunakan program SPSS 24 diperoleh taraf signifikan dari nilai adalah residual KS dari data yang diuji sebesar 0,200. Oleh karena taraf signifikan pengujian $(0,200>$ $0,05)$ sehingga dapat diasumsikan bahwa data motivasi belajar, adversity quotient, disimpulkan bahwa data varians populasi merupakan homogen.

3. Uji multikolinearitas

Berdasarkan hasil analisis dengan menggunakan dengan menggunakan program SPSS 24 diperoleh nilai tolerance $0,703>0,10$ dan nilai VIF sebesar $1,422<$ 10 maka antara variabel bebas tidak terjadi multikolinearitas.

4. Uji autokorelasi

Berdasarkan hasil analisis dengan menggunakan program SPSS 24 diperoleh taraf signifikan run test 0,141 . Karena taraf signifikan run test lebih dari taraf signifikan pengujian maka tidak terjadi gejala autokorelasi.

5. Uji hipotesis penelitian

Berdasarkan hasil perhitungan dapat digambarkan sebagai berikut.

$$
R_{2}^{2}=0,456
$$

$\varepsilon_{2}=0,738$

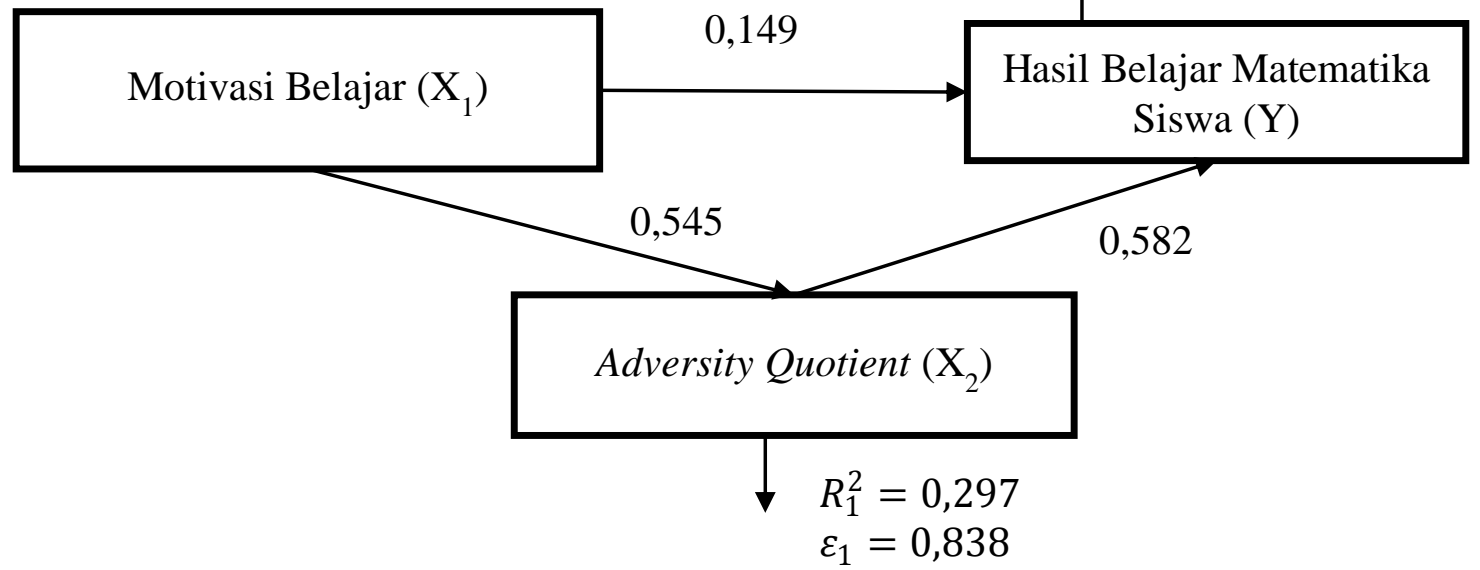

Gambar 2. Hubungan antar variabel

data motivasi belajar, adversity quotient dan nilai hasil belajar matematika merupakan populasi yang berdistribusi normal.

2. Uji heteroskedastisitas

Teknik perhitungan B-P-G test diperoleh nilai $\chi^{2}{ }_{h i t}=0,491$ dan $\chi^{2}{ }_{t a b}=$ 5,591. Karena $\chi^{2}{ }_{h i t}<\chi_{\text {tab }}^{2}$ maka dapat

\section{Hipotesis 1}

$H_{0}$ : Tidak terdapat pengaruh motivasi belajar terhadap adversity quotient

$H_{1}$ : Terdapat pengaruh motivasi belajar terhadap adversity quotient

Berdasarkan hasil analisis diperoleh koefisien jalur antara $X_{1}$ dan $X_{2}$ sebesar 0,545 dan taraf sig.t sebesar 0,000 karena 
taraf sig statistik < taraf sig. pengujian $(0,05)$, sehingga disimpulkan bahwa $H_{1}$ diterima atau terdapat pengaruh langsung motivasi belajar terhadap adversity quotient.

\section{Hipotesis 2}

$H_{0}$ : Tidak terdapat pengaruh motivasi belajar dan adversity quotient terhadap hasil belajar matematika.

$H_{1}$ : Terdapat pengaruh motivasi belajar dan adversity quotient terhadap hasil belajar matematika.

Berdasarkan hasil analisis diperoleh koefisien jalur antara $X_{1}$ dan $Y$ sebesar 0,149 dengan taraf sig.t sebesar 0,025, koefisien jalur antara $X_{2}$ dan $Y$ sebesar 0,582 dan taraf sig.t sebesar 0,000, sehingga disimpulkan bahwa $H_{1}$ diterima atau terdapat pengaruh motivasi belajar dan adversity quotient terhadap hasil belajar matematika.

\section{Hipotesis 3}

$H_{0}$ : Tidak terdapat pengaruh tidak langsung motivasi belajar terhadap hasil belajar matematika melalui adversity quotient

$H_{1}$ : Terdapat pengaruh tidak langsung motivasi belajar terhadap hasil belajar matematika melalui adversity quotient

Berdasarkan hasil analisis diperoleh koefisien jalur antara $X_{1}$ dan $X_{2}$ sebesar 0,545 serta koefisien jalur antara $X_{2}$ dan $Y$ sebesar 0,582, sehingga didapat koefisien jalur $X_{1}$ terhadap $Y$ melalui $X_{2}=0,545 \times 0,582=$ 0,317 dengan taraf sig.t sebesar 0,000 , maka disimpulkan bahwa $H_{1}$ diterima atau terdapat pengaruh tidak langsung motivasi belajar terhadap hasil belajar matematika melalui adversity quotient.

\section{KESIMPULAN}

Berdasarkan hasil penelitian dapat disimpulkan bahwa:

1. Terdapat pengaruh motivasi belajar terhadap adversity quotient siswa kelas VII SMP Negeri 10 samarinda tahuan ajaran 2019/2020.

2. Terdapat pengaruh motivasi belajar secara langsung terhadap hasil belajar matematika siswa kelas VII SMP Negeri 10 Samarinda tahun ajaran 2019/2020.

3. Terdapat pengaruh motivasi belajar secara tidak langsung terhadap hasil belajar matematika melalui adversity quotient siswa kelas VII SMP negeri 10 Samarinda tahun ajaran 2019/2020.

\section{DAFTAR PUSTAKA}

Adisasmito, Lilik. (2007). Mental Juara: Modal Atlet Berprestasi. Jakarta: Raja Grafindo persada.

Adz-Dzakiey, Hamdani Bakran. (2005). Prophetic Intelligence Kecerdasan Kenabian. Yogyakarta: Islamika.

Amir, Zubaidah dan Risnawati. (2016). Psikologi Pembelajaran Matematika. Yogyakarta: Aswaja Pressindo.

Departemen Pendidikan Nasional. 2007. Kamus Besar Bahasa Indonesia Edisi 3. Jakarta: Balai Pustaka.

Komarudin. (2013). Psikologi Olahraga: Latihan Mental Dalam Olahraga Kompetitif. Bandung: Remaja Rosdakarya.

Kurniadin, Didin dan Imam Machali. (2016). Manajemen Pendidikan. Yogyakarta: Ar-Ruzz Media.

Mustofa, Bisri. (2015). Psikologi Pendidikan. Yogyakarta: Paranama. 
Nashori. (2007). Adversity Quotient: Hambatan Menjadi Peluang. Jakarta; Grasindo.
Uno, Hamzah. (2013). Teori Motivasi dan Pengukurannya. Jakarta: Bumi Aksara. 